\title{
2690. Balance asymmetry properties evaluation for people who are more and less likely to suffer from trauma
}

\author{
Kęstutis Radžiūnas ${ }^{1}$, Margarita Radžiūnienè르. Tomas Čiuželis ${ }^{3}$, Alfonsas Vainoras ${ }^{4}$, \\ Jonas Poderys ${ }^{5}$ \\ Lithuanian University of Health Sciences, Institute of Sports, Kaunas, Lithuania \\ ${ }^{5}$ Lithuanian Sports University, Institute of Sport Science and Innovations, Kaunas, Lithuania \\ ${ }^{1}$ Corresponding author \\ E-mail: ${ }^{1}$ kestutis.radziunas@fc.lsmuni.lt, ${ }^{2}$ margarita.radziuniene@fc.lsmuni.lt, \\ 3tomas.ciuzelis@fc.lsmuni.lt, ${ }^{4}$ alfavain@gmail.com, ${ }^{5}$ jonas.poderys@lsu.lt
}

Received 20 April 2017; received in revised form 4 November 2017; accepted 13 November 2017 DOI https://doi.org/10.21595/jve.2017.18518

Abstract. More and more people suffer from trauma and it depends on the functional movement, balance characteristics. Balance management is based on the interaction of the systems of skeletal muscles and nerves and it is important to know what the reason of traumas is for people who are more or less likely to suffer from trauma. The aim of our research was to determine the balance characteristics asymmetry properties for people who are more and less likely to suffer from trauma. The study involved 382 people aged 18-24 years. The study consisted of functional movement and balance evaluation. Seven functional movements were assessed as per the G. Cook's criteria and according to this the subjects were divided into groups. The balance was tested on the Libra balance platform. Results obtained during the study demonstrate the feasibility of presented testing methodology to access individual peculiarities and to evaluate of effects of exercise training program. Participants who are less likely to suffer from trauma have a better balance in the frontal and sagittal planes, while they are standing with both legs with open or closed eyes on an unstable balance platform.

Keywords: physical function, functional performance, fitness, motor control.

\section{Introduction}

Movement is the basis of the human growth and development of motor skills. Movement is a lifelong necessity [4]. Many authors state that the rehabilitation approach to the assessment of human body has changed from the traditional approach - isolated assessment and enhancement of one weak link to the integrated functional approach, including the principles of neuromuscular proprioception, the methods of motor perception, and muscular synergy [6, 12]. The assessments of one segment: the assessment of the range of movements, personal physical data, and specific muscle group are usually carried out, but there is no observable correlation between the results obtained, which aggravate the comprehensive assessment of personal physical fitness level and the quality of the movement performed [7]. The quality of movement, which is important in people's every day and sporting life, is rarely assessed. After assessing the movement by qualitative assessment methods, the weak links are better observed [5].

The main function of torso muscles at the optimum muscle endurance is to keep the torso upright [35]. Proper torso muscle endurance and proper torso muscles activity are associated with a good posture, as well as the absence of torso muscles overload and pain [9].

Balance is the ability to maintain a stable body position in various positions when moving under the influence of external forces [14]. The balance is of two types: static balance that is the ability to maintain the body position stationary, in the stable position [38], and dynamic balance that is the body posture maintenance in changing body positions while making movements and their combinations [24]. The static and dynamic balance is not very closely related to each other with a good static balance, a person may have difficulties when performing the tasks of dynamic balance [23]. 
Balance management is based on the interaction of the systems of skeletal muscles and nerves that is necessary to maintain the desired position of the body segments, and the stable position $[26,28]$. Balancing stability is largely determined by the joint amplitude, spinal flexibility, mechanical properties of muscles, and the biomechanical correlation of the body segments [17].

There are a lot of factors, influencing the balance: vestibular apparatus, information from external and internal receptors, functionality of the central nervous system, age, changes of the body mass center, emotional state, muscle strength, muscle activation, coordination, flexibility, level of training, motor development, genetics, and gender [1, 14, 20, 34, 38, 42]. Good balance depends on the accepted signals to the central nervous system (CNS) from visual, vestibular, and proprioceptive systems [37]. Good correlation of the visual and somatosensory information was obtained by the CNS results in the full-rate orientation of the body segments, stability, and movement [18]. Good balance is maintained by contracting and relaxing the muscles to which nerve impulses are transmitted from the CNS.

Functional movements are the ability to perform properly, easily, painlessly the body movements through the articular surfaces, using muscles [40]. Properly performed functional movements are important in daily, general physical activity, and sport [27]. Well-performed functional movements are important to human well-being and traumas prevention [10].

If a person is constantly moving with the poor posture, improper body mechanics, the movements are not performed in the full amplitudes of the joints, and bones cannot move freely through the articular surfaces, it may result in the restriction of movements and muscle imbalances [13]. Individual movements, which the combinations make functional movements, may also cause traumas $[25,33]$.

Functional movements are usually assessed for sportsmen, athletes [3, 22, 36], but in recent years the assessment of functional movements is popular in the health assessment of physically active amateur sportsmen and students $[11,19,21]$. The assessment of functional movements and their correct performance is important, otherwise compensatory mechanisms, which lead to the decrease of physical abilities and the increase of the risk of traumas, dominate there [41]. Functional movements and their stereotypes are expedient, coordinated combinations of mobile and stable segments, working in one direction that leads to productive and efficient human movements. The aim of these combinations is to maintain the human body stability, balance and adaptability to the changing environmental conditions during the active movement $[6,7]$.

The assessment of functional movement performance is also important because of the human brain processes $[16,30]$. When performing targeted movements, stereotyped movements are formed in the human brain [16]. Stereotypes must create harmonious, productive, efficient and economic movements. When muscles and joints movements are isolated, having pain or dysfunction, the stereotype will be irregular, and the compensating movements will be created to maintain the incomplete functionality $[4,5]$. These compensational movements are a mechanism that will not become distinct when analyzing and examining one joint or one muscle group [15].

The components of physical fitness are related to the performance of specific tasks in the assessment of human physical characteristics [2]. With appropriate physical fitness, the body tends to withstand greater physical loads [29]. The aim of our research was to determine functional movement, balance characteristics, physical fitness components and torso muscles endurance asymmetry properties for people who are more and less likely to suffer from trauma.

\section{Methods}

Study design. The study involved 382 right-hand people aged 18-24. The study was carried out in the Lithuanian University of Health Sciences, Institute of Sports in 2015.

Participants. All the participants were involved voluntarily; they didn't have any acute or chronic disease.

Outcomes and measurements. The testing took place once. The study consisted of the assessment of balance and functional movement. Functional movement screen was taken for the 
reason to divide the subjects into groups. The assessment was carried out according to the same protocol for all the participants.

\subsection{Functional movement screen (FMS)}

When assessing the performance of stereotyped functional movements, the study participants were acquainted in detail with the test performance. Participants took 7 standardized functional movement tests. This methodology can assess the performance of stereotyped functional movements, and promotes testing the interactions between the kinetic links. This methodology is not designed to diagnose problems, but to see the stereotypic movement restrictions, asymmetries, and to help achieving more precise improvement of the quality of movement, and increasing trauma prevention at the same time. The participants conducted performance assessment tests of functional movements in a certain order. Per the assessment of final FMS, two groups were divided: the data of the participants, who received 14 and less points, was analyzed in the group, which was more likely to suffer from trauma. The participants who received 15 and more points were assigned to the group, which was less likely to suffer from trauma.

\subsection{Balance evaluation}

Balance was assessed using a computerized balance platform (Italy, 2002, 93/42/CEE). The system consists of a $42 \times 42 \mathrm{~cm}$ platform, computer, and computer system. Each participant performed 6 exercises on this platform. The testing took 3 minutes for each participant. Each of 6 tests lasted 30 seconds. The balance was evaluated in both the frontal (Fig. 1(a)) and sagittal (Fig. 1(b)) planes while the participant was standing.

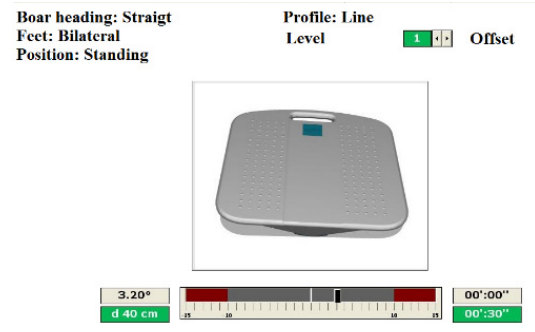

a)

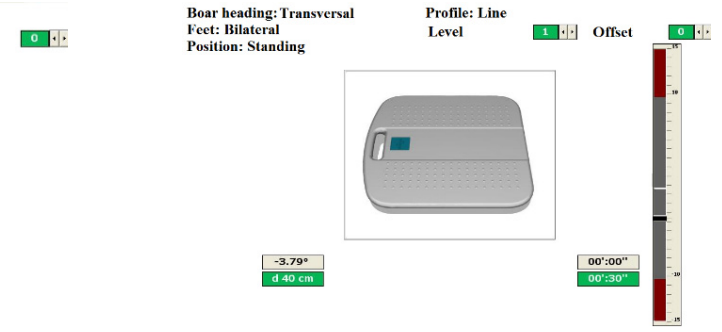

b)

Fig. 1. Computer screen while participants took the first and fourth tests:

a) frontal plane, b) sagittal plane [31]

The first 3 tests were taken in the sagittal plane, and the other 3 tests were in the frontal plane. The first and fourth tests were conducted with feedback - participants saw a white small line on the computer screen and tried to hold a black small line on it. The aim is to be as straight as possible. The second and fifth tests were taken in different planes without feedback (Fig. 2).

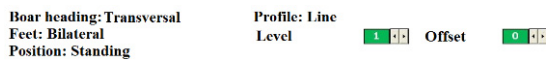

00':00"'
00':30"

Fig. 2. Computer screen while participants took the second and fifth tests [31]

For the third and sixth tests, participants performed with closed eyes. All these tests were taken standing with straight knees, and, as noted by the requirement for participants, they should not bend their knees. All movements should be focused on one body segment-hips. 
Accumulated data were processed by a computer program. Exercise performance was measured on the right and left: total area [ $\left.{ }^{\circ} \mathrm{sec}\right]$, external area [ $\left.{ }^{\circ} \mathrm{sec}\right]$, external time [sec], recovery time [sec] (Fig. 3). From these four numbers, the summative assessment (Fig. 4) was evaluated (ranging from 0 to 100). A lower value of summative assessment means a better balance. Total score was calculated using a software algorithm, comparing the left and right sides of the body - deviation from the midline of the results. It is also called as the stability index, it is based on the weighted average of all the variables, where ' 100 ' denotes the weakest stability, and ' 0 ' denotes the best one. The algorithm of summative assessment (stability index) calculation is (total area (left) + total area (right) + external area (left) + external area (right) + external time (left) + external time $($ right $)+$ recovery time $($ left $)+$ recovery time $($ right $)) / 8$.

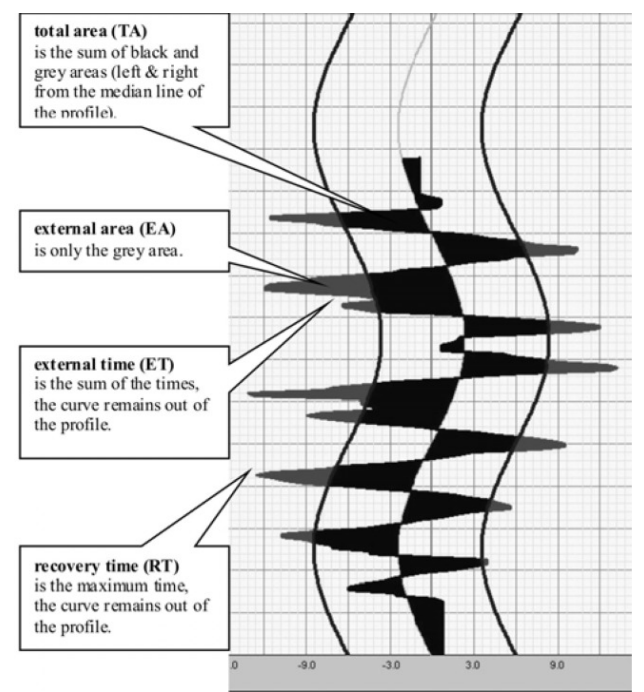

Fig. 3. Meaning of fluctuation [31]

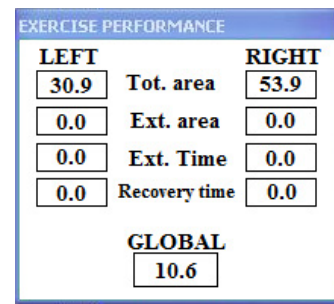

Fig. 4. Summative assessment calculation

Statistical analysis. The analysis of statistical data was performed by using the program package SPSS (Statistical Package for Social Sciences) 22.0 for Windows. The difference between two independent groups was tested using the Mann-Whitney U test. While the difference before and after physical therapy was calculated using the Wilcoxon matched pairs rank test. Nonparametric tests were used because the research data was based on fewer assumptions they did not assume that the outcome had been approximately normally distributed. The significance level $p<0.05$ was used for the verification of statistical hypotheses. Data were presented as median $\left(x_{m e}\right)$, first quartile $\left(Q_{1}\right)$ third quartile $\left(Q_{3}\right)$ and mean $(\bar{x})-x_{m e}\left(Q_{1}-Q_{3} ; \bar{x}\right)$ (Fig. 5).

Ethics statement. The permission (No.BE-2-46, 07/10/2014) was obtained from by the Lithuanian Regional Biomedical Research Ethics Committee in order to carry out the study. Written informed consent was obtained from all the participants. The data was processed after obtaining the permission (No. 2R-6211 (2.6-1), 04/12/2014) of the State Data Protection Inspectorate. 


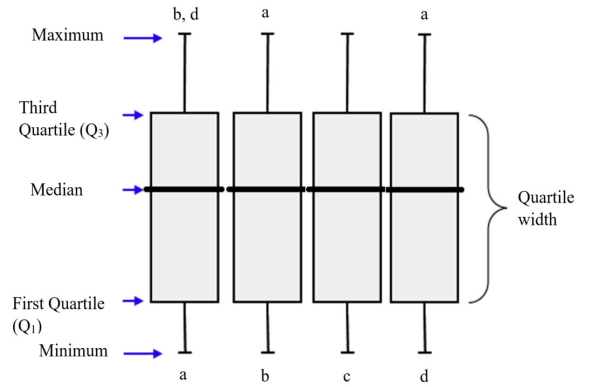

Fig. 5. Data graphs providing: a-d - column imaginary index. Denotations "a-d", situated at the top of the rectangular diagram, represent statistically significant difference $(p<0,05)$ with the diagram of the named index. For example, the column value "a" was statistically and significantly different from the column values "b" and "d"

\section{Results}

Participant recruitment. Baseline characteristics are in the 1st Table.

Table 1. Body height and weight of participants

\begin{tabular}{|c|c|c|c|c|}
\hline Group & Distribution & Height $(\mathrm{m})$ & Weight $(\mathrm{kg})$ & Age $(\mathrm{m})$. \\
\hline I group & $\begin{array}{c}253(66 \%): \\
\text { More likely to suffer from trauma }\end{array}$ & & & \\
& $\begin{array}{c}172(32 \%) \text { men; } \\
\text { II }(68 \%) \text { women }\end{array}$ & $1.72 \pm 0.09$ & $67.33 \pm 13.05$ & $19.12 \pm 0.96$ \\
\hline II group & $\begin{array}{c}129(34 \%) \\
37(29 \%) \text { men; }\end{array}$ & $1.74 \pm 0.09$ & $65.80 \pm 11.63$ & $19.08 \pm 0.45$ \\
Less likely to suffer from trauma & $92(71 \%)$ women & & & \\
\hline
\end{tabular}

The assessment of balance for young people, who are more or less likely to suffer from trauma.

After assessing the stability index of the participants who were more or less likely to suffer from trauma, when performing the balance task with the open eyes, with and without a feedback in the frontal and sagittal planes, the difference was not obtained. Both groups performed these four tasks equally. After assessing the performance of balance task with the closed eyes in the frontal plane, it was determined that this task had been better performed by the participants who were less likely to suffer from trauma, but this difference was not obtained when performing this task in sagittal plane with the open eyes (Fig. 6), (Tables 2-3).

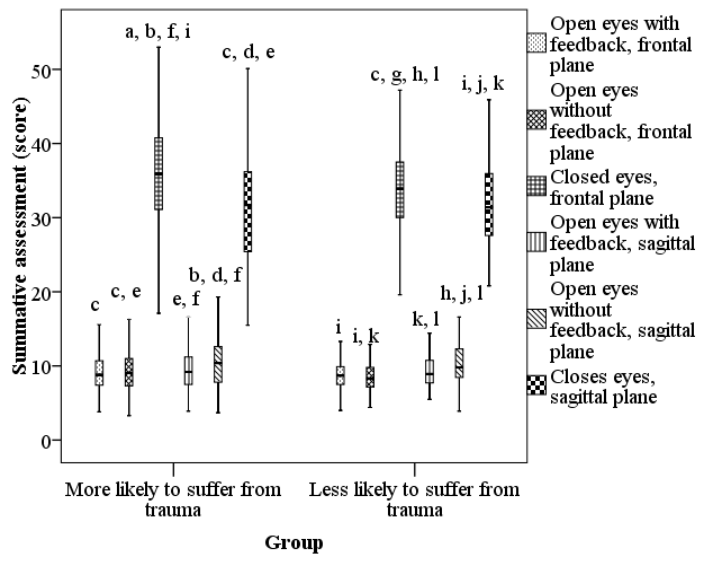

Fig. 6. Comparison of people who are more or less likely to suffer from trauma balance, in frontal and sagittal planes (a-m identification of columns $-p<0.05$ ) 
2690. BALANCE ASYMMETRY PROPERTIES EVALUATION FOR PEOPLE WHO ARE MORE AND LESS LIKELY TO SUFFER FROM TRAUMA.

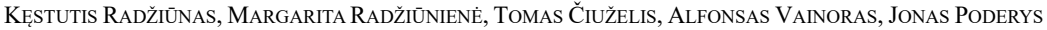

Table 2. Median, first quartile - third quartile, mean and test criteria of both groups stability index results of frontal and sagittal plane

\begin{tabular}{|c|c|c|c|c|}
\hline & & $\begin{array}{c}\text { More likely to suffer from } \\
\text { trauma }\end{array}$ & $\begin{array}{c}\text { Less likely to suffer } \\
\text { from trauma }\end{array}$ & Test criteria \\
\hline \multirow{4}{*}{$\begin{array}{c}\text { Frontal } \\
\text { plane }\end{array}$} & With feedback & $8.8(7.4 ; 10.7 ; 9.5)$ & $8.7(7.5 ; 9.9 ; 8.9)$ & $\begin{array}{c}U=7506.5 ; \\
p=0.375\end{array}$ \\
\cline { 2 - 6 } & $\begin{array}{c}\text { Without } \\
\text { feedback }\end{array}$ & $9.1(7.3 ; 11.0 ; 9.6)$ & $8.3(7.2 ; 9.8 ; 8.7)$ & $\begin{array}{c}U=6899.5 ; \\
p=0.061\end{array}$ \\
\cline { 2 - 6 } & Closed eyes & $35.9(31.1 ; 40.8 ; 35.7)$ & $33.9(30 ; 37.5 ; 33.9)$ & $\begin{array}{c}U=6800.5 ; \\
p=0.042\end{array}$ \\
\hline \multirow{4}{*}{$\begin{array}{c}\text { Sagittal } \\
\text { plane }\end{array}$} & With feedback & $9.2(7.5 ; 11.2 ; 9.8)$ & $8.9(7.7 ; 1.8 ; 9.3)$ & $\begin{array}{c}U=7692.5 ; \\
p=0.554\end{array}$ \\
\cline { 2 - 6 } & $\begin{array}{c}\text { Without } \\
\text { feedback }\end{array}$ & $10.4(7.8 ; 12.6 ; 10.7)$ & $9.8(8.5 ; 12.3 ; 10.3)$ & $\begin{array}{c}U=8000.0 ; \\
p=0.925\end{array}$ \\
\cline { 2 - 6 } & Closed eyes & $31.7(25.4 ; 36.2 ; 1.5)$ & $31.4(27.6 ; 36 ; 32)$ & $\begin{array}{c}U=7690.0 ; \\
p=0.551\end{array}$ \\
\hline
\end{tabular}

Table 3. Test criteria of both groups stability index results of frontal and sagittal plane

\begin{tabular}{|c|c|c|c|c|}
\hline & \multicolumn{2}{|c|}{ More likely to suffer from trauma } & \multicolumn{2}{|c|}{ Less likely to suffer from trauma } \\
\hline & Frontal plane & Sagittal plane & Frontal plane & Sagittal plane \\
\hline Wit & \multirow{2}{*}{$\begin{array}{c}Z=-0.051 \\
p=0.959\end{array}$} & \multirow{2}{*}{$\begin{array}{c}Z=-4.213 \\
p<0.001\end{array}$} & \multirow{2}{*}{$Z=-0.777 ; p=0.437$} & \multirow{2}{*}{$\begin{array}{c}Z=-3.026 \\
p=0.002\end{array}$} \\
\hline Withou & & & & \\
\hline With feedback & \multirow{2}{*}{$\begin{array}{c}Z=-12.385 \\
p<0.001\end{array}$} & \multirow{2}{*}{$\begin{array}{c}Z=-12.373 \\
p<0.001\end{array}$} & \multirow{2}{*}{$\begin{array}{c}Z=-7.722 \\
p<0.001\end{array}$} & \multirow{2}{*}{$\begin{array}{c}Z=-7.722 \\
p<0.001\end{array}$} \\
\hline Closed eyes & & & & \\
\hline Without feedback & $Z=-12.351$ & $Z=-12.383$ & $Z=-7.722$ & $Z=-7.722$ \\
\hline Clos & $p<($ & & & \\
\hline
\end{tabular}

When analyzing which task was performed better, it was observed that the tasks with the open eyes with a feedback, and with the open eyes without a feedback in the frontal plane had been equally performed. In the sagittal plane, both groups performed better the task with a feedback in comparison with the task without a feedback. Both in the sagittal, and frontal planes, the results of the balance task with the closed eyes were worse than those when performing the tasks with the open eyes with a feedback or without it in both groups (Fig. 6).

Frontal plane, total area (Table 4).

When analyzing the results of the participants on how much they leaned to the right and to the left during the balance tasks performing, it was observed that when performing the tasks in the frontal plane, both the participants, who were more likely to suffer from trauma, and the participants, who were less likely to suffer from trauma, had equally leaned to the left, when performing the tasks with the open eyes and without a feedback, and with the closed eyes (Fig. 7). When performing the tasks with the open eyes with a feedback and with the closed eyes, the participants of both groups had leaned equally to the right. When performing the task with the open eyes, without a feedback, the participants who were more likely to suffer from trauma, had leaned more to the right.

When analyzing the side, to which the participants of the groups leaned more, it was obtained that when performing the task with the open eyes with a feedback, both the participants, who were more likely to suffer from trauma, and the participants, who were less likely to suffer from trauma, had equally leaned to the left, and to the right. When performing the tasks with the open eyes, without a feedback and with the closed eyes, it was obtained that the participants, who were more likely to suffer from trauma, and who were less likely to suffer from trauma, had leaned to the right (Fig. 8) (Test criteria in Table 4).

Sagittal plane, the total area (Table 4).

When analyzing the data in the sagittal plane, the participants leaning forward and backward were assessed in the performance of balance tasks. Both the participants, who were more likely to 
suffer from trauma, and the participants, who were less likely to suffer from trauma, performed equally all three tasks in the sagittal plane (Fig. 9).

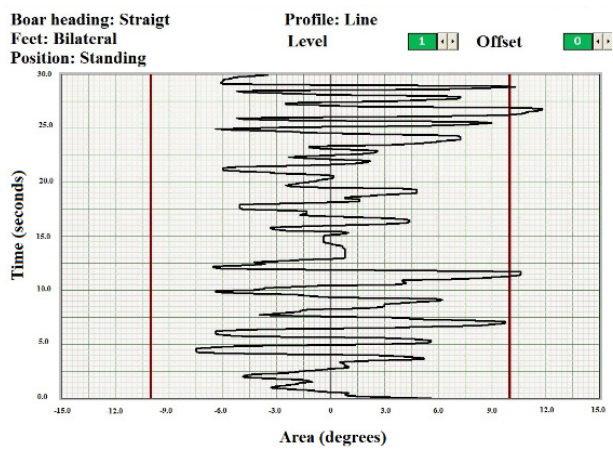

a)

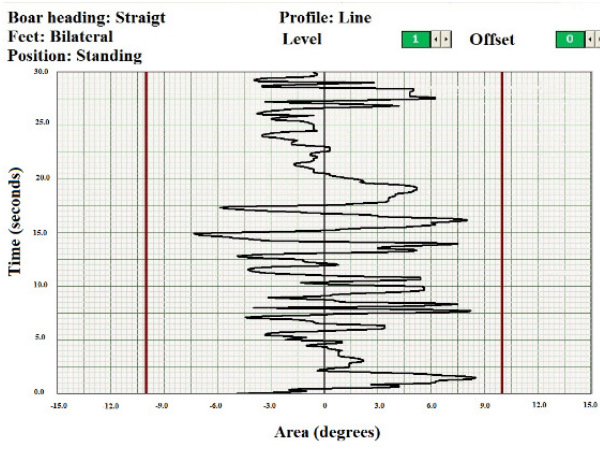

b)

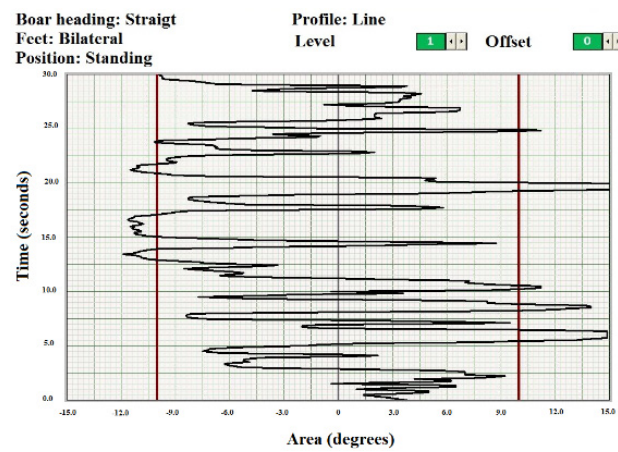

c)

Fig. 7. Fluctuation while participants took performance in frontal plane:

a) with feedback, b) without feedback, c) with closed eyes

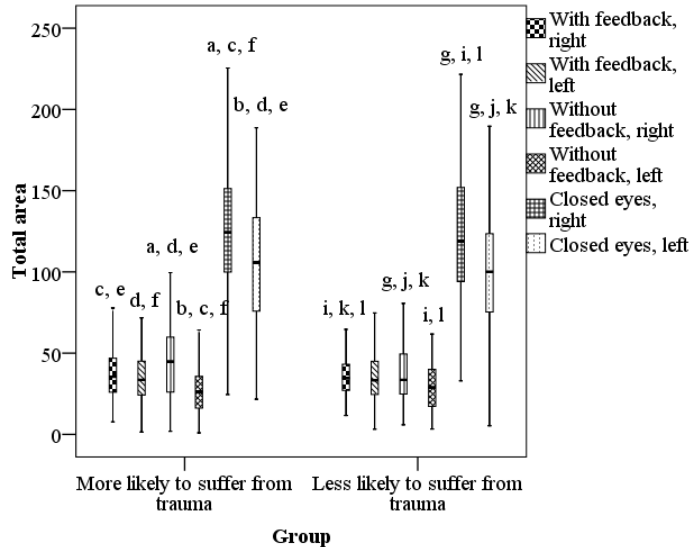

Fig. 8. Comparison of people who are more or less likely to suffer from trauma total area to the left or right, in frontal plane (a-k identification of column, $p<0.05$ )

When analyzing, where the participants leaned more - forward or backward, it was obtained that when performing the tasks with the open eyes (both with a feedback, and without it), the participants of both groups had leaned backwards more. When performing the task with the closed eyes, the participants of both groups had leaned equally both forward, and backward (Fig. 10) (Test criteria in Table 4). 


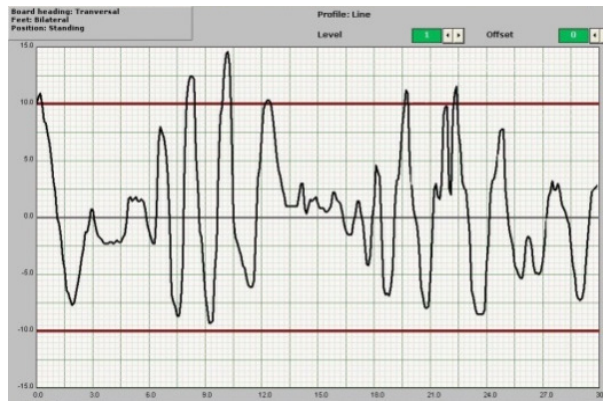

a)

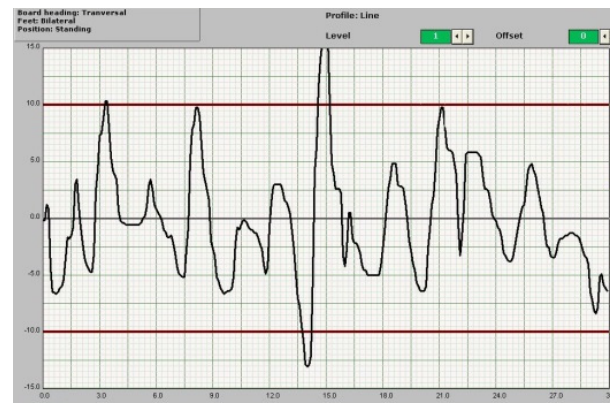

b)

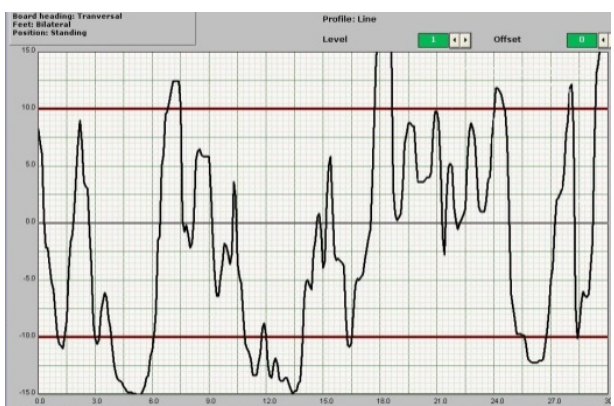

c)

Fig. 9. Fluctuation while participants took exercise in sagittal plane:

a) with feedback, b) without feedback, c) with closed eyes

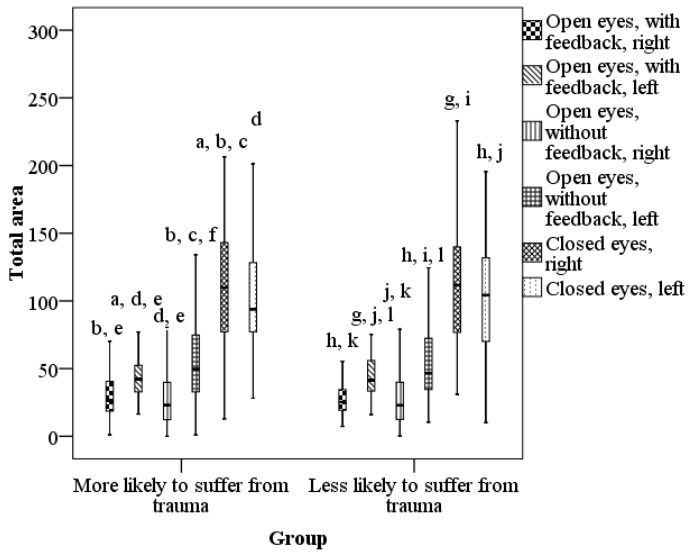

Fig. 10. Comparison of people who are more or less likely to suffer from trauma total area to the left or right, in sagittal plane (a-k identification of column, $p<0.05$ )

\section{Discussion}

The researchers studied the young officers balance (men and women) ( $n=1466$, age 24.7), lifestyle dependence, physical fitness, risk factors and probability to suffer of trauma. The conclusions of this study state that people, who had at least one risk factor, had a poorer balance than those who didn't have any risk factor [39]. In our study, we did not evaluate the risk factors of lifestyle, such as inappropriate weight, smoking, previous traumatic events, but we assessed persons more and less likely to suffer from trauma. In our research, we found that there was a statistically significant difference between groups - the participants, who are less suffer from trauma, had a better balance with open and closed eyes in frontal and sagittal plane.

The researchers, who studied the balance with open and closed eyes for 18-25 years old 
basketball players, state, that there is no difference between different performances. The balance is the same for basketball players who took a task with open or closed eyes [8]. In our research, we got a statistically significant difference between different tasks. Differences between these two researches might be because we evaluated the healthy young people balance, the other authors were 21 young basketball players.

Table 4. Median, first quartile - third quartile, mean and test criteria of both groups results of staying in right or left (frontal plane) and forward and backwards (sagittal plane) (degrees per seconds)

\begin{tabular}{|c|c|c|c|c|c|}
\hline & & & $\begin{array}{c}\text { More likely to suffer from } \\
\text { trauma }\end{array}$ & $\begin{array}{c}\text { Less likely to suffer from } \\
\text { trauma }\end{array}$ & Test criteria \\
\hline \multirow{9}{*}{$\begin{array}{l}\text { Frontal } \\
\text { plane }\end{array}$} & \multirow{2}{*}{$\begin{array}{c}\text { With } \\
\text { feedback }\end{array}$} & Right & $35.5(30 ; 46.9 ; 39.2)$ & $34.6(27.1 ; 43.2 ; 36.2)$ & $\begin{array}{c}U=7602.0 ; \\
p=0.460\end{array}$ \\
\hline & & Left & $33.6(24.3 ; 45.1 ; 35.8)$ & $33.3(24.6 ; 45 ; 34.7)$ & $\begin{array}{c}U=7963.5 \\
p=0.878\end{array}$ \\
\hline & \multicolumn{2}{|c|}{ Test criteria } & $\begin{array}{c}Z=-1.733 \\
p=0.083\end{array}$ & $\begin{array}{c}Z=-0.398 \\
p=0.690\end{array}$ & \\
\hline & \multirow{2}{*}{$\begin{array}{l}\text { Without } \\
\text { feedback }\end{array}$} & Right & $44.9(26 ; 59.9 ; 46.1)$ & $33.6(24.8 ; 49.5 ; 38)$ & $\begin{array}{c}U=6531.0 \\
p=0.013\end{array}$ \\
\hline & & Left & $26.3(16.2 ; 35.7 ; 29.2)$ & $28.9(17.2 ; 40.1 ; 30.7)$ & $\begin{array}{c}U=7521.5 \\
p=0.385\end{array}$ \\
\hline & \multicolumn{2}{|c|}{ Test criteria } & $\begin{array}{c}Z=-3.245 \\
p=0.001\end{array}$ & $\begin{array}{c}Z=-0.225 \\
p=0.822\end{array}$ & \\
\hline & \multirow{2}{*}{ Closed eyes } & Right & $124.4(99.9 ; 151.3 ; 126.1)$ & $118.9(94 ; 152 ; 127.6)$ & $\begin{array}{c}U=7603.5 \\
p=0.462\end{array}$ \\
\hline & & Left & $105.8(75.9 ; 133.4 ; 105.7)$ & $100.1(75.4 ; 123.5 ; 99.7)$ & $\begin{array}{c}U=7372.5 \\
p=0.267\end{array}$ \\
\hline & \multicolumn{2}{|c|}{ Test criteria } & $\begin{array}{c}Z=-4.437 \\
p<0.001\end{array}$ & $\begin{array}{c}Z=-2.524 \\
p=0.012\end{array}$ & \\
\hline \multirow{9}{*}{$\begin{array}{l}\text { Sagittal } \\
\text { plane }\end{array}$} & \multirow{2}{*}{$\begin{array}{c}\text { With } \\
\text { feedback }\end{array}$} & Forwards & $26.5(18.6 ; 40.6 ; 30.1)$ & $25.3(19.2 ; 34.5 ; 29.1)$ & $\begin{array}{c}U=7716.0 ; \\
p=0.580\end{array}$ \\
\hline & & Backwards & $42.3(32.9 ; 52.5 ; 45.2)$ & $41.4(33.4 ; 56 ; 44.2)$ & $\begin{array}{c}U=7917.5 ; \\
p=0.820\end{array}$ \\
\hline & \multicolumn{2}{|c|}{ Test criteria } & $\begin{array}{c}Z=-0.194 \\
p=0.846\end{array}$ & $\begin{array}{c}Z=-0.862 \\
p=0.389\end{array}$ & \\
\hline & \multirow{2}{*}{$\begin{array}{l}\text { Without } \\
\text { feedback }\end{array}$} & Forwards & $23.1(12.3 ; 39.9 ; 29.4)$ & $23(12.5 ; 40 ; 29.1)$ & $\begin{array}{c}U=7987.0 \\
p=0.908\end{array}$ \\
\hline & & Backwards & $49.6(32.9 ; 74.8 ; 55)$ & $46.7(34.6 ; 72.5 ; 52.2)$ & $\begin{array}{c}U=7721.0 \\
p=0.585\end{array}$ \\
\hline & \multicolumn{2}{|c|}{ Test criteria } & $\begin{array}{c}Z=-1.383 \\
p=0.167\end{array}$ & $\begin{array}{c}Z=-0.491 \\
p=0.623\end{array}$ & \\
\hline & \multirow{2}{*}{ Closed eyes } & Forwards & $109.8(77.1 ; 143.2 ; 111.1)$ & $111.7(76.7 ; 140 ; 111.5)$ & $\begin{array}{c}U=7990.0 \\
p=0.912\end{array}$ \\
\hline & & Backwards & $93.8(77.3 ; 128.3 ; 101.1)$ & $104.3(70.1 ; 131.9 ; 103.2)$ & $\begin{array}{c}U=7624.0 ; \\
p=0.482\end{array}$ \\
\hline & \multicolumn{2}{|c|}{ Test criteria } & $\begin{array}{c}Z=-0.948 \\
p=0.343\end{array}$ & $\begin{array}{c}Z=-0.057 \\
p=0.955\end{array}$ & \\
\hline
\end{tabular}

For explanation the results obtained during our study are very valuable the study results obtained by researchers from Slovenia [32]. The balance abilities with twisted legs analyses for 18 young people was assessed. Participants had to stay 70 seconds on the unstable platform or before losing the balance. Participants were standing in four different conditions: daylight, closed eyes, with darkened light, and full darkness with open eyes. Researches state that the balance is statistically significant different while participants took the same performance and daylight and darkened light. The conclusions of this research state that there are bigger fluctuations while 
participants took performances with closed eyes and in the full darkness than in the daylight or in the darkened light [32]. In our study, we got that for both groups had been more difficult to perform the balance tasks when the eyes had been closed. There were also statistically significant differences between the balance tasks with or without feedback for the both groups.

Functional movement testing requires to integrate the data of seven functional movements testing procedures $[24,41]$. This takes a long time why the health professionals need for the other methods allowing to assess of such complex interaction of factors defining the individual balance asymmetry properties and evaluate the effectivity of exercise training programs. Results obtained during this study showed that testing of balance characteristics asymmetry properties could provide such useful information.

Kęstutis Radžiūnas made an experiment, wrote an introduction, analysis of results, discussions, conclusions. Margarita Radžiūnienė made a statistical analysis, a part of analysis of the results, discussion. Tomas Čiuželis helped doing a part of experiment. Alfonsas Vainoras helped creating the research methodology, discussion, conclusions. Jonas Poderys created the research methodology, helped writing conclusions.

\section{Conclusions}

Results demonstrate the feasibility of presented testing methodology to access individual peculiarities and to evaluate of effects of exercise training program.

Participants who are less likely to suffer from trauma have a better balance in the frontal and sagittal planes, while they are standing with both legs with open or closed eyes on an unstable balance platform.

\section{References}

[1] AlAbdulwahab S., Kachanathu S. Effects of body mass index on foot posture alignment and core stability in a healthy adult population. Journal of Exercise Rehabilitation, Vol. 12, Issue 3, 2016, p. $182-187$.

[2] Aras D., Akalan C. Sport rock climbing: as a type of physical activity to improve health-related physical fitness parameters. The Journal of Sports Medicine and Physical Fitness, 2015, p. 1-8.

[3] Bakken A., Targett S., Bere T., Eirale C., Farooq A., Tol J., et al. Association between rowing injuries and the functional movement screen in female collegiate division I rowers. International Journal of Sports Physical Therapy, Vol. 11, Issue 3, 2016, p. 345-349.

[4] Cook G., Burton L., Hoogenboom B., Voight M. Functional movement screening: the use of fundamental movements as an assessment of function - Part 2. International Journal of Sports Physical Therapy, Vol. 9, Issue 4, 2014, p. 549-563.

[5] Cook G., Burton L., Hoogenboom B., Voight M. Functional movement screening: the use of fundamental movements as an assessment of function - Part 1. International Journal of Sports Physical Therapy, Vol. 9, Issue 3, 2014, p. 396-409.

[6] Cook G., Burton L., Hoogenboom B. Pre-participation screening: the use of fundamental movements as an assessment of function - Part 2. North American Journal of Sports Physical Therapy, Vol. 1, Issue 3, 2006, p. 132-139.

[7] Cook G., Burton L., Hoogenboom B. Pre-participation screening: the use of fundamental movements as an assessment of function - Part 1. North American Journal of Sports Physical Therapy, Vol. 1, Issue 2, 2006, p. 62-72.

[8] Dabadghav R. Correlation of ankle eversion to inversion strength ratio and static balance in dominant and non-dominant limbs of basketball players. The Journal of Sports Medicine and Physical Fitness, Vol. 56, Issue 4, 2016, p. 422-427.

[9] Dejanovic A., Harvey E., McGill S. Changes in torso muscle endurance profiles in children aged 7 to 14 years: reference values. Archives of Physical Medicine and Rehabilitation, Vol. 93, Issue 12, 2012, p. 2295-2301.

[10] Forte R., Boreham C., De Vito G., Pesce C. Health and Quality of Life Perception in Older Adults: The Joint Role of Cognitive Efficiency and Functional Mobility. International Journal of Environmental Research and Public Health, Vol. 12, Issue 9, 2015, p. 11328-11344. 
2690. BALANCE ASYMMETRY PROPERTIES EVALUATION FOR PEOPLE WHO ARE MORE AND LESS LIKELY TO SUFFER FROM TRAUMA.

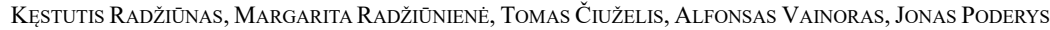

[11] Glass S., Ross S. Modified functional movement screening as a predictor of tactical performance potential in recreationally active adults International Journal of Sports Physical Therapy, Vol. 10, Issue 5, 2015, p. 612-621.

[12] Hoogenboom B., Voight M., Cook G., Gill L. Using rolling to develop neuromuscular control and coordination of the core and extremities of athletes. North American Journal of Sports Physical Therapy, Vol. 4, Issue 2, 2009, p. 70-82.

[13] Hrysomallis C. Injury incidence, risk factors and prevention in Australian rules football. Sports Medicine, Vol. 43, Issue 5, 2013, p. 339-354.

[14] Huang H., Ahmed A. Tradeoff between stability and maneuverability during whole-body movements. PLoS One, Vol. 6, Issue 7, 2011, p. 1-10.

[15] Yamako G., Deng G., Totoribe K., Chosa E. Muscle activity pattern dependent pain development and alleviation. Journal of Orthopaedic Science, Vol. 21, Issue 4, 2016, p. 517-523.

[16] Yamako G., Deng G., Totoribe K. A Novel protocol to test age-related decreases in sit-to-stand movement abilities in healthy subjects. Journal of Orthopaedic Science, Vol. 21, Issue 4, 2016, p. 517-523.

[17] Juodžbalienė V., Muckus K. The influence of the degree of visual impairment on psychomotor reaction and equilibrium maintenance of adolescents. Medicina, Vol. 42, Issue 1, 2006, p. 49-56.

[18] Kamandulis S., Venckūnas T., Masiulis N., Matulaitis K., Balčiūnas M., Peters D., et al. Relationship between general and specific coordination in 8- to 17-year-old male basketball players. Perceptual and Motor Skills, Vol. 117, Issue 3, 2013, p. 821-836.

[19] Kazman J., Galecki J., Lisman P., Deuster P., O'Connor F. Factor structure of the functional movement screen in marine officer candidates. The Journal of Strength and Conditioning Research, Vol. 28, Issue 3, 2014, p. 672-678.

[20] Kilroy E., Crabtree O., Crosby B., Parker A., Barfield W. The effect of single-leg stance on dancer and control group static balance. International Journal of Exercise Science, Vol. 9, Issue 2, 2016, p. $110-120$.

[21] Letafatkar A., Hadadnezhad M., Shojaedin S., Mohamadi E. Relationship between functional movement screening score and history of injury. International Journal of Sports Physical Therapy, Vol. 9, Issue 1, 2014, p. 21-27.

[22] Lockie R., Schultz A., Callaghan S., Jordan C., Luczo T., Jeffriess M. A Preliminary investigation into the relationship between functional movement screen scores and athletic physical performance in female team sport athletes. Biology of Sport, Vol. 32, Issue 1, 2015, p. 41-51.

[23] Maeda N., Urabe Y., Tsutsumi S., Numano S., Morita M., Takeuchi T., et al. Effect of semi-rigid and soft ankle braces on static and dynamic postural stability in young male adults. Journal of Sports Science and Medicine, Vol. 15, Issue 2, 2016, p. 352-357.

[24] Nam H., Cha H., Kim M. The effects of exercising on an unstable surface on the gait and balance ability of normal adults. Journal of Physical Therapy Science, Vol. 28, Issue 7, 2016, p. 2102-2104.

[25] Nelson M., Rejeski W., Blair S., Duncan P., Judge J., King A., et al. Physical activity and public health in older adults: recommendation from the American College of Sports Medicine and the American Heart Association. Medicine and Science in Sports and Exercise, Vol. 39, Issue 8, 2007, p. $1435-1445$.

[26] Nonnekes J., Carpenter M., Inglis J., Duysens J., Weerdesteyn V. What startles tell us about control of posture and gait. Neuroscience and Biobehavioral Reviews, Vol. 53, 2015, p. 131-138.

[27] Olsen A., Strand L., Skjaerven L., Sundal M., Magnussen L. Patient education and basic body awareness therapy in hip osteoarthritis - a qualitative study of patients' movement learning experiences. Disability and Rehabilitation, 2016, p. 1-8.

[28] Oomen N., Reeves N., Priess M., van Dieën J. Trunk muscle coactivation is tuned to changes in task dynamics to improve responsiveness in a seated balance task. Journal of Electromyography and Kinesiology, Vol. 25, Issue 5, 2015, p. 765-772.

[29] Pedrero Chamizo R., Gómez Cabello A., Meléndez A., Vila Maldonado S., Espino L., Gusi N., et al. Higher levels of physical fitness are associated with a reduced risk of suffering sarcopenic obesity and better perceived health among the elderly: the EXERNET multi-center study. The Journal of Nutrition Health and Aging, Vol. 19, Issue 2, 2015, p. 211-217.

[30] Portas M., Parkin G., Roberts J., Batterham A. Maturational effect on Functional Movement Screen $^{\mathrm{TM}}$ score in adolescent soccer players. Journal of Science and Medicine in Sport, Vol. 19, Issue 10, 2016, p. 854-858. 
2690. BALANCE ASYMMETRY PROPERTIES EVALUATION FOR PEOPLE WHO ARE MORE AND LESS LIKELY TO SUFFER FROM TRAUMA. KęSTUtis RadŽIŪNAS, MARgarita RADŽIŪNIENĖ, TOMAS ČIUŽElis, AlFONSAS VAINORAS, JONAS PODERYS

[31] Radžiūnienė M., Mauricienė V., Berškienė K., Vanagas G., Radžiūnas K. Improvement of balance of children with disorder of motor function by means of adapted physiotherapy. Journal of Vibroengineering, Vol. 18, Issue 5, 2016, p. 3292-3304.

[32] Rugelj D., Gomišček G., Sevšek F. The influence of Very low illumination on the postural sway of young and elderly adults. PLoS One, Vol. 9, Issue 8, 2014.

[33] Schneiders A., Davidsson A., Hörman E., Sullivan S. Functional movement screen normative values in a young, active population. International Journal of Sports Physical Therapy, Vol. 6, Issue 2, 2011, p. $75-82$.

[34] Stanković M., Radenković O. The status of balance in preschool children involved in dance program. Research Kinesiol, Vol. 40, Issue 1, 2012, p. 113-116.

[35] Šiupšinskas L., Vitartaitė A., Sendžikaitė E., Zachovajevienė B. Physical health assessment of a person. LSMU Publishing House, Kaunas, 2013, (in Lithuanian).

[36] Tafuri S., Notarnicola A., Monno A., Ferretti F., Moretti B. CrossFit athletes exhibit high symmetry of fundamental movement patterns. A cross-sectional study. Muscles, Ligaments and Tendons Journal, Vol. 6, Issue 1, 2016, p. 157-160.

[37] Taguchi C., Teixeira J., Alves L., Oliveira P., Raposo O. Quality of life and gait in elderly group. International Archives of Otorhinolaryngology, Vol. 20, Issue 3, 2016, p. 235-240.

[38] Talebi H., Karimi M., Abtahi S., Fereshtenejad N. Static balance in patients with vestibular impairments: a preliminary study. Scientifica, 2016, p. 1-4.

[39] Teyhen D., Rhon D., Butler R., Shaffer S., Goffar S., Mcmillian D., et al. Association of physical inactivity, weight, smoking, and prior injury on physical performance in a military setting. Journal of Athletic Training, Vol. 51, Issue 11, 2016, p. 866-875.

[40] Teyhen D., Shaffer S., Lorenson C., Greenberg M., Rogers S., Koreerat C., et al. Clinical measures associated with dynamic balance and functional movement. The Journal of Strength and Conditioning Research, Vol. 28, Issue 5, 2014, p. 1272-1283.

[41] Voight M., Hoogenboom B., Cook G. The Chop and lift reconsidered: integrating neuromuscular principles into orthopedic and sports rehabilitation. North American Journal of Sports Physical Therapy, Vol. 3, Issue 3, 2008, p. 151-159.

[42] Zalewski C. Aging of the human vestibular system. Seminars in Hearing, 2015; 36(3): p. 175-196.

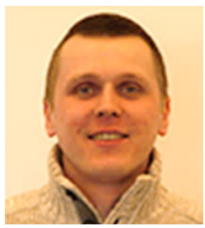

Kęstutis Radžiūnas is a last year Ph.D. Student. He works in a profession school. His current research interests are young people health.

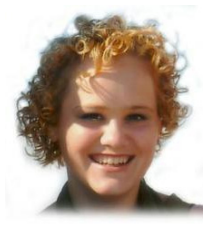

Margarita Radžiūnienè received a Ph.D. (Biomedicine Sciences) in 2016. Now she works in the Lithuanian University of Health Sciences, Institute of Sports. Her research interests are infants, babies and children health.

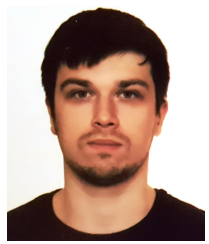

Tomas Čiuželis has a Master degree. Now he works in the Hospital of Lithuanian University of Health Sciences Kauno Klinikos Department "Kulautuva's Rehabilitation Hospital". Research interests: exercise programs effectiveness patients with low back pain, neck pain or muscle hypotonus, rehabilitation after stroke. 


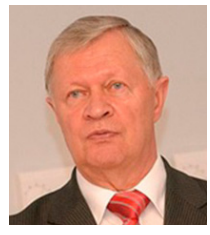

Habil. Dr. Alfonsas Vainoras is Professor of the Lithuanian University of Health Sciences, Kaunas, Lithuania. Research interests: development of functional test evaluation, edification; investigation of human organism reactions to different influences, formalization of reactions, development of systems for integral evaluations.

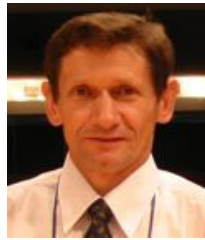

Habil. Dr. Jonas Poderys is professor of the Lithuanian University of Health Sciences, Kaunas, Lithuania, and the Institute of Sport Science and Innovations of the Lithuanian Sports University. Research interests: the muscle blood flow and the work ability; the body's functional state complex evaluation; human health and work improvement. 